\title{
Teaching Novice Science Teachers Online: Considerations for Practice-Based Pedagogy
}

\author{
Allison J. Gonsalves, Emily Diane Sprowls, and Dawn Wiseman
}

\begin{abstract}
The COVID-19 pandemic has required educators at all levels to pivot instruction online. In this article, we consider methods we adopted to engage novice science teachers in approximations of teaching, online. We describe the principles of our science teacher education program and provide a rationale for the core feature of our science teaching methods course: practice-based pedagogy. We then discuss adaptations we have made to engage novices in ambitious science teaching practices online, and the affordances and constraints the virtual context posed to these practices. We conclude with a discussion of considerations for online practice-based pedagogy.

The COVID-19 pandemic has had a dramatic impact on teaching at all levels. In an attempt to contain the spread of the SARS CoV-2 virus, schools have closed around the world, affecting hundreds of millions of learners (UNESCO, 2020). In Canada, postsecondary institutions have almost universally pivoted to online learning. We are instructors for science teaching methods courses at two postsecondary institutions in Quebec. Like all educators, our roles have been challenged by the context of the COVID-19 pandemic. We have had to shift to remote instruction for novice teachers and adapt our approach to teacher education, which relies on interactive pedagogies of practice (Grossman et al., 2009; Jao et al., 2018). In our science teacher education programs, this has meant offering highly interactive methods classes in a virtual environment, finding tools to both adapt to the online space and to offer opportunities for novice teachers to learn and practice skills that will be used in face-to-face instruction. Online instruction in the context of a global pandemic requires many considerations that go beyond the question: "How do we adapt for remote learning?" We also need to consider challenges to the core features of our science teaching methods courses. In this paper, we outline these core features and discuss how they are affected by remote instruction. We then detail the adaptations we made to move our methods courses online and provide reflections on these changes and the ongoing challenges the virtual learning poses to science teacher education.
\end{abstract}

\section{Background: Ambitious Science Teaching and Model-Based Inquiry}

The goals of our science teaching methods courses are to develop novice teachers' understanding and practice of ambitious science teaching (AST) (e.g., Windschitl et al., 2012; Windschitl et al., 2018)_ science teaching that deliberately aims to enable students to understand big science ideas, participate in the discourses of the discipline, and engage with ideas of science in meaningful and authentic ways. AST opens up science to the breadth of student experiences because it begins with students' experiences of the world and then requires that students "talk out" their thinking with teachers and peers in ways that 
entail co-thinking and co-constructing with others to make sense of scientific ideas (Windschitl et al., 2008). AST outlines a research- and practice-based approach to teaching. It has been shown to support educators (both pre- and in-service) in developing practices that engage students in real-world questions (inquiry) and problems (problem solving); base teaching in big ideas of science and technology (Harlen, 2010; MELS, 2006); and develop scientific and technological understandings, skills, and language over time. It is thus a solid foundation for science and technology teacher education that aligns with the related competencies of the science programs within the Quebec Education Program (QEP). More specifically, the AST framework breaks the processes of science and technology teaching into four practices: 1) Planning for engagement with big scientific and technological ideas; 2) Eliciting student ideas and prior knowledge; 3) Supporting ongoing changes in student thinking through engagement with data and data collection; and 4) Drawing together evidence-based explanations based on data (Windschitl et al., 2018).

Planning to teach in the manner suggested by AST parallels the process used to design and implement Learning Evaluation Situations (LES), the assessment method favoured in the QEP (MELS, 2006). Once novice teachers have experienced ambitious science teaching in action, they are expected to build an LES based on anchoring phenomena. Each LES is developed using backwards design, where students write a complete explanation for the phenomenon to help them identify disciplinary understandings and how they are related in ways that help explain the phenomenon. This explanation and identified disciplinary understandings then serve as the basis for developing the scope and sequence of lessons within the LES — one of which will be rehearsed and enacted in the methods course.

AST anchors learning around natural phenomena and essential questions related to the phenomena. Anchoring phenomena are observable in the real world, but require developing understandings across scientific disciplines in order for students to explain what is happening at both the macro (observable) and micro (unobservable) levels. For example, an anchoring phenomenon could be a video of a tanker car imploding accompanied by a story of how the tank had been steam cleaned, but the valve had been sealed immediately following the cleaning, and then left in the cold temperatures overnight (see Windschitl \& Thompson, 2013, for details). The related essential question might be, "Why did the tanker car implode?" In order to explain this phenomenon, students need to pull together understandings about how matter and energy interact through phase changes of water, to yield a story that details the relationships between temperature, volume, and pressure and how they interact with the strength and integrity of materials. The exploration of this phenomenon occurs over several lessons so students can collect data and move towards evidence-based explanations of the phenomenon. In this way, students develop conceptual understandings of progressions of learning related to matter, phase changes, gas laws (temperature, volume, pressure, etc.), and materials, and can also connect those understandings to related phenomena that draw on similar big ideas, such as the deflation of bicycle or car tires in the winter.

To support changes in student thinking, we use a specific form of instruction called "Model-Based Inquiry" (MBI: Windschitl et al., 2008). In MBI, students construct models of the phenomenon (usually by drawing) to facilitate their understanding, and to identify both observable and unobservable events taking place in the phenomenon. MBI begins in small groups, and then the instructor convenes the whole group to establish a "consensus model" which brings together understandings from all students in the class 
towards a collective understanding of the underlying reasoning for the phenomenon. The process of instruction is highly collaborative, involving interactions between the instructor and students (eliciting student thinking), and between students (to generate collective understandings).

Throughout AST practices there is emphasis on student and teacher discourse, written and oral expression, connections to mathematical reasoning, modeling, and ongoing assessment of students. AST also assumes that practices are modeled by the teacher educator, then rehearsed and enacted by novice teachers as a means of developing their understanding of what this approach actually looks and feels like in the classroom. Given the emphasis on eliciting students' thinking and prior knowledge, and supporting changes in student thinking, a focus of our science teacher education courses is on learning and practicing responsiveness to student thinking. That is, noticing and responding to student thinking as it arises, and then using appropriate core practices (McDonald et al., 2013) that are likely to support students in developing enduring understandings of science. This requires that novice teachers learn specific discourse strategies (e.g., probing, pressing, wait time; Windschitl et al., 2018) to elicit students' understandings of scientific ideas, and then scaffold students' understandings by pressing for evidence based on data students have generated. The role of the teacher in an AST context is not to deliver information, but rather to facilitate student talk and to negotiate understanding among students. Learning to engage in this very interactive and student responsive form of teaching requires novice teachers to observe and deconstruct practices modeled by their instructor(s) and to rehearse those practices with peers. In the following sections, we describe aspects of practice-based pedagogy in our science methods courses that facilitate these opportunities, followed by our reflections on pivoting to online learning and teaching.

\section{Practice-Based Pedagogy in Our Teacher Education Programs}

Our approach to science teacher education is guided by the following principles:

- Teaching is a complex craft that can be learned and developed over time.

- Teaching is learned best through practice and connecting that practice to theory.

- Part of learning to teach is reflecting on and critiquing your own practice based on evidence of student learning.

We elaborate on these principles here, since we wish to consider the complexities of retaining these core principles as we have changed our course offerings to online environments.

We try to convey through our courses that good teaching is learned over time and with practice. A core feature of our courses thus focuses on building in opportunities to practice teaching in a setting of reduced complexity, within a community of professionals and learners (Grossman et al., 2009). These teaching opportunities are "approximations of teaching" (Grossman et al., 2009), as they provide scaffolded opportunities to learn and try out practices known to elicit students' thinking and make studentresponsive instructional decisions. To introduce novice teachers to AST, as teacher educators we first demonstrate core instructional practices and student responsiveness through the enactment of an instructional activity in which novice teachers act as students. Throughout the teaching demonstration, 
the teacher educator pauses to explicitly define a practice (e.g., eliciting students' prior knowledge, or representing student thinking), points to decisions made in the moment (e.g., how student thinking is being responded to), and reflects on evidence of student learning. The teacher educator also talks through responses to student thinking, or pedagogical dilemmas (e.g., what to do with a student's idea that doesn't "fit" with the instructional goals) to demonstrate how to make instructional decisions that authentically respond to students' ways of thinking (Kavanagh et al., 2020).

We then construct situations where the novice teachers plan and rehearse their own instructional activity in a classroom of their peers. We regard these rehearsals as approximations of practice because they require novice teachers to plan and teach lessons where they enact practices (such as discourse moves to elicit student thinking), but the setting involves considerably fewer distractions and complications than a real classroom. The goal of the rehearsal is not just to rehearse practices-it is also to learn how to notice and respond to students' thinking (e.g., Lampert et al., 2013), and to make instructional decisions in response to dilemmas that arise in teaching (Kavanagh et al., 2020) in the moment. The role of the teacher educator in a rehearsal can be to interject if the novice teacher veers off course, to remind them of their instructional goals, to help them to deconstruct a practice, or to understand how to respond to students' thinking in authentic ways. Novices are not evaluated on their teaching practice. Rather, we emphasize that the opportunity to engage in approximations of teaching is entirely a learning process, and provides material for reflection, both individually, as co-teachers, and within their community of learning. We provide many opportunities for novice co-teachers to receive feedback on their teaching from the teacher educator and from the peers in their class, and their rehearsals are video recorded so they may engage in structured reflections of their own practice.

The move to online learning raised concerns for us about how we would model and rehearse practices that elicit student thinking, but moreover, how we would build in opportunities for novice teachers to learn and practice activities where students are participants in developing understanding, rather than recipients of knowledge (Moje, 2015). In what follows, we describe the settings in which our courses took place, and then we detail two practices (demonstrating and rehearsing instruction) and the modifications we needed to make to enable a student responsive environment. We discuss the affordances and limitations the online environment provides for this form of teacher education.

\section{Context}

In this paper, we offer perspectives of online and hybrid instruction from one single secondary science teaching course, co-taught by Allison and Emily, the first and second authors. We work in collaboration with Dawn, the third author, who teaches elementary and secondary science methods courses at a different institution. Here we offer perspectives that come from collaborative instruction: Allison and Emily's co-instruction of the course, but also the co-design of the course in collaboration with Dawn, with whom we consulted regularly as we all worked to pivot our courses online. As none of us had ever taught online courses prior to this pandemic-related shift, we frequently shared strategies and concerns as we planned and taught our courses in the summer leading up to the fall term, and during the fall term. We collaboratively analyzed the affordances and constraints of our course adaptations, but to streamline 
our discussion here, we describe the most salient changes from one course only. While we situate our discussion in one course as an example, our concerns and reflections emerge from our collective planning and conversations across both courses and institutions.

Our secondary teacher certification program is offered at both the Bachelor of Education (BEd) level and the Masters of Teaching and Learning (MATL) level. Both programs have small secondary science teaching cohorts of approximately 9-15 students. The course we discuss in this paper is offered to the MATL science teaching cohort, a group of 10 novice teachers who have not yet completed a field experience in schools and who have varied practical experiences teaching in context. Some of the novices in this course are currently working as uncertified secondary science teachers, while others have not entered into a secondary science classroom since completing their own secondary education. All of them have at least bachelor-level science degrees already. None of the novices in this group had any exposure to AST methods, MBI, or even the QEP-based learning and evaluation situations. The classes we describe here are those where we specifically demonstrate ambitious instruction (week 4) and the rehearsals done by the novices (weeks 10-12). All lessons were synchronous, and took place via Zoom, an online meeting tool which is integrated into our university's learning management software. We also recorded all lessons on Zoom, so that we could reflect on them after the course, and for any novices who were unable to attend synchronous classes.

\section{Demonstrating Teaching Practices}

In our programs, we typically introduce novice teachers to AST practices by demonstrating them via an instructional activity, and at the same time we "pause" instruction to deconstruct and analyze practice (e.g., Jao et al., 2018; Lampert et al., 2013). In this course, we elected to offer this practice in a hybrid fashion, demonstrating instruction in person for only a few novice teachers (four) and offering synchronous online and recorded instruction to the remainder of the class. Thus, we had a video camera and a microphone/speaker set up in the classroom to project instruction and classroom discussions online, and to involve those at home in the discussion by projecting their online presence onto a screen in the classroom so students in class and at home could have discussions while observing the demonstration of practice. Research has demonstrated that actually drawing out visual representations is critical for enabling model-based reasoning (e.g., Quillin \& Thomas, 2015; Stieff \& DeSutter, 2021). Therefore, as we wished to retain this collaborative practice, we used an online whiteboard (Google Jamboard) for modeling, where novices were asked to talk about their important science ideas and collaboratively sketch them using the drawing tools on Google Jamboard.

\section{Hybrid Instruction}

Hybrid instruction requiring access to laboratory equipment proved challenging. To maintain social distancing and hygiene practices, each student had to work independently and have their own sets of equipment. This meant precisely planning out activities, including all movements within the classroom. No experiments could be conducted for which the instructors had not anticipated the needed supplies, and no tests that involved novices having to congregate around a workstation. The instructor also had a 
set of equipment, on which the video camera was directed for the novices observing the class from home. Novices at home were provided in advance with an equipment list of materials commonly found at home if they wanted to follow along, however none of them did. As we were demonstrating a phenomenon and testing out variables, novices working from home were able to make suggestions to the instructor for variables to test, while those novices in the classroom were able to test their own ideas. We collectively recorded data on a Google Jamboard, so that novices in class and at home could participate in data collection. Any videos or slides that were used to supplement the lesson needed to be provided to novices ahead of time for those joining at home.

\section{Collaborative Tools}

Online whiteboard tools like the Jamboard provide opportunities for students to contribute to consensus modeling in real time. As all novice teachers were logged into the Jamboard (both at home and in class), they could all contribute their claims and evidence to the model as we talked through our understandings of the phenomenon. An example is provided in Figure 1. This was a "consensus model" for the puzzling phenomenon, "What caused the tank car to implode?" In this consensus model, we could agree on the parameters of the diagram (e.g., before, during, and after), and one novice was assigned to draw. Other novices could type in observations and hypotheses as they became relevant and add sticky notes with questions as they arose.

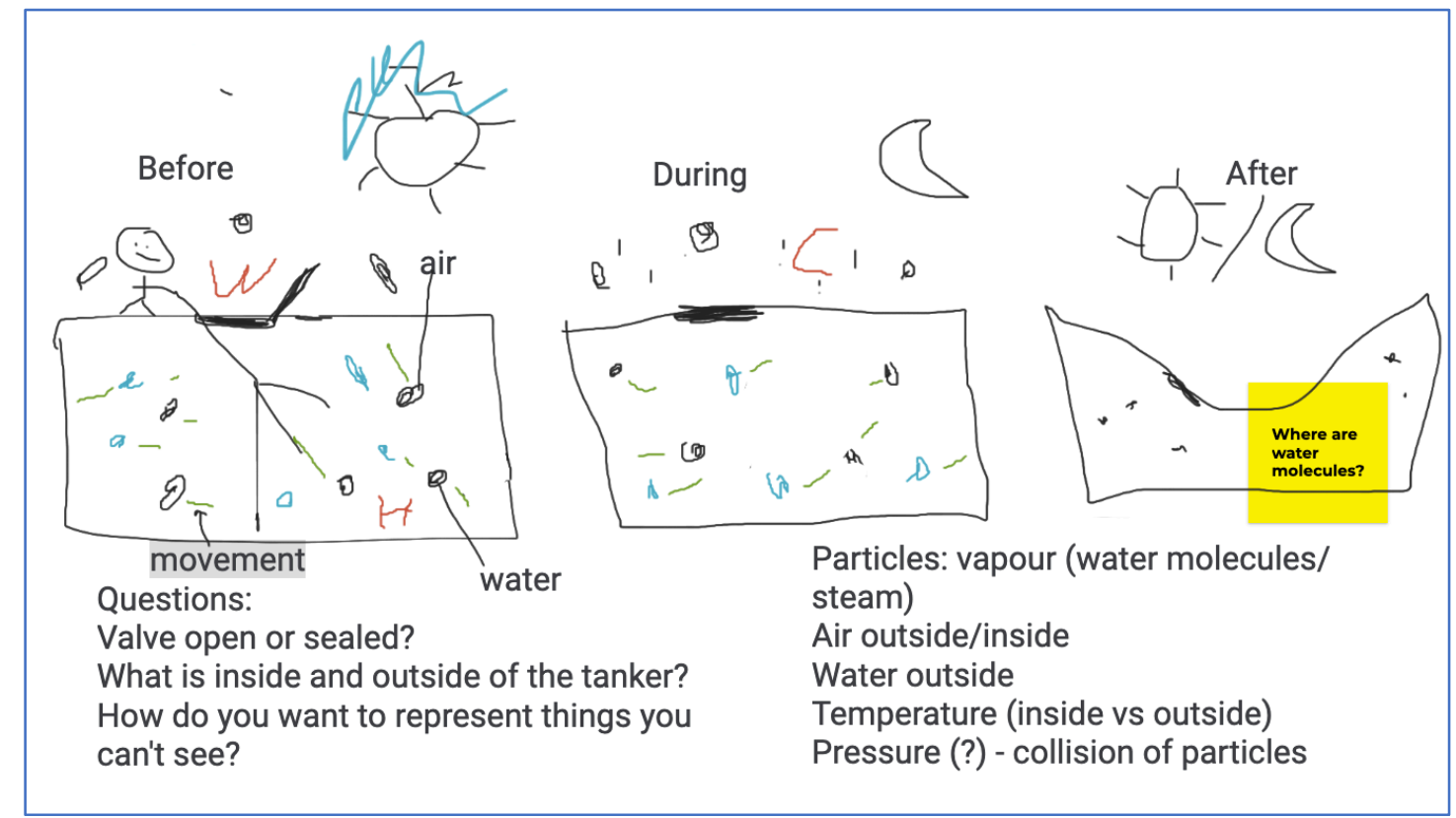

Fig. 1: Consensus modeling online. Teacher educator and novices can collaboratively contribute to collection of evidence, question posing, and representing student thinking.

As the class was hybrid, we also made use of physical whiteboards in the classroom, to represent and keep a record of student thinking (e.g., Jao et al., 2018). On the classroom whiteboards, we recorded observations and novices' initial explanations or hypotheses related to the phenomenon. This practice 
was useful for the novices who were present in class, but it was challenging to see for those at home. We addressed this by taking photographs of the whiteboards, and uploading them to the Jamboard, so that novices online could also have a record of student thinking (see Fig. 2).

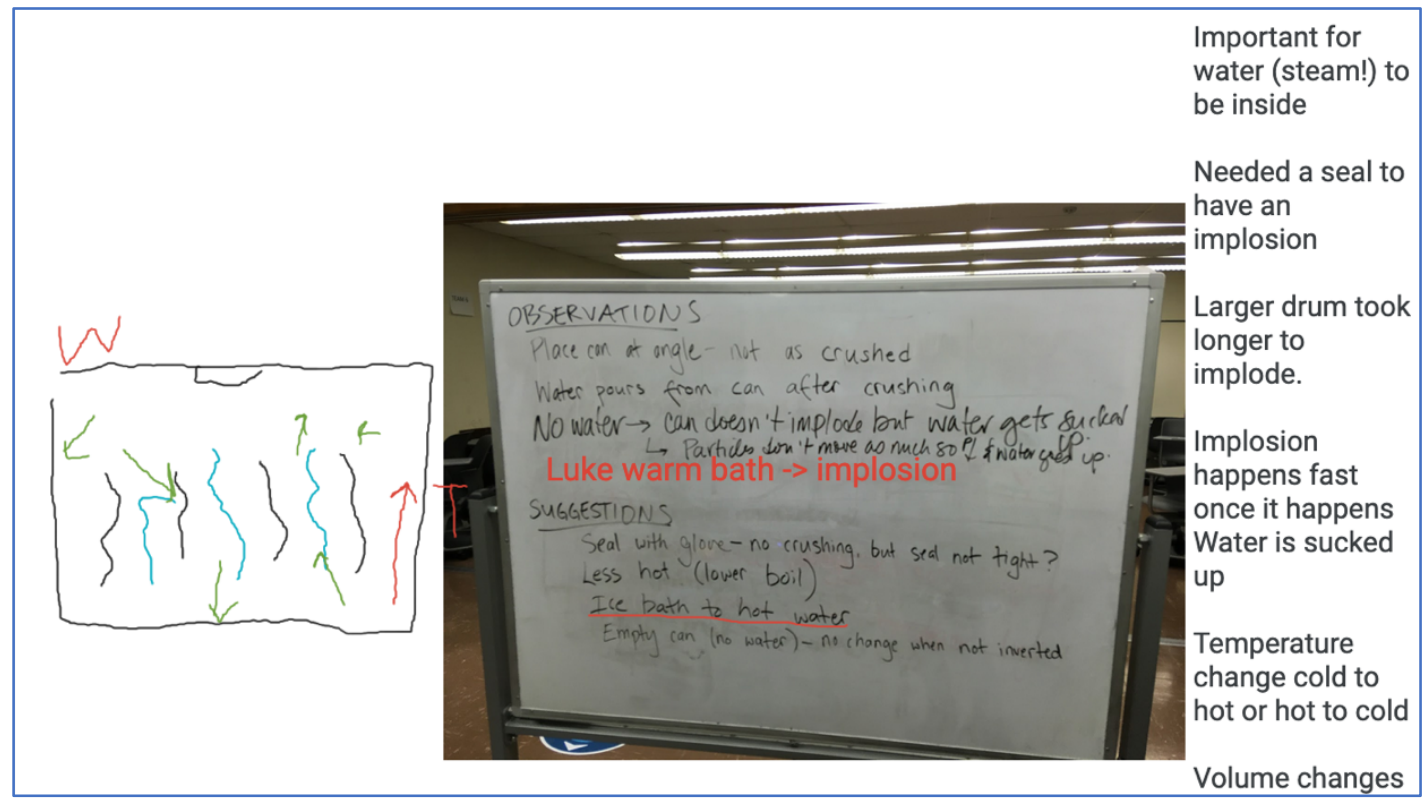

Fig. 2: A whiteboard within a whiteboard. Integrating in-class whiteboards into online whiteboards to represent student thinking.

\section{Reflections on Hybrid Instruction}

There were many moving parts to the lesson. We juggled demonstration with equipment, in-person novices testing with their own laboratory set-up, novices at home recommending tests, collective data collection, small- and whole-group discussions. The teacher educator was constantly moving between in-person conversations with novice teachers and online conversations, and thus it was challenging to address our primary instructional goal of facilitating "student talk" in this context. As we watched the recording of this class, we noticed that the teacher educator spent the majority of the time talking. The teacher educator used a lot of wait time, which sometimes generated responses from students online, but the majority of interjections from novice teachers happened from those who were present in the classroom. Comments from novices online only came when the teacher educator specifically addressed them. Those in the room who were constantly in the view of the teacher educator tended to contribute to classroom discussion more spontaneously. Hybrid practice thus raised questions about how attentive the instructor was to all students, as the in-person students gained more attention from the instructor, and conversation was more fluid in the classroom context than in the virtual context. Additionally, this activity is meant to demonstrate teaching in an environment of reduced complexity (Grossman et al., 2009). The hybrid format described here created a number of complexities that may have detracted from the goals of the activity: to demonstrate discourse practices that elicit student thinking, and to model opportunities to make instructional decisions based on students' ideas. Further, by the point in the 
semester when novices were ready to conduct their own rehearsals, tighter COVID-related restrictions limited in-person teaching, so their rehearsals happened entirely online. We describe these next.

\section{Rehearsals as Approximations of Teaching: Adaptations for Online Practice}

The lesson rehearsal is the main approximation task of the course, which requires novice teachers to engage in practices that elicit and respond to student thinking about science phenomena. Planning for the rehearsal requires selecting a puzzling phenomenon that illustrates a big idea of science (Harlen, 2010), and that requires students to spend time modeling and discussing to develop consensus explanations. In the online rehearsals, novices had to select phenomena that they could easily show on camera, or a video that could convey the phenomenon. A typical rehearsal is already constrained by time (usually 30 minutes) and thus anchoring activities need to be "doable" within that time frame. This short timeframe is one of the ways the rehearsal approximates teaching. However, the online setting poses additional pedagogical hurdles.

\section{Representing Student Thinking}

Typically for in-person rehearsals, novices make use of whiteboards and document projectors in the classroom, as well as the projector for any slides they may wish to show. Whiteboards are used to keep a record of student thinking, such as observations, prior experiences, and initial hypotheses. Document cameras can be used to project small group paper and pencil-drawn models to the whole class, as students share initial ideas and begin co-constructing understanding. In the online environment, novices are limited to using online tools. This requires additional planning and rethinking about how they wish to represent student thinking. There are numerous tools available for novices to use to represent student thinking: online whiteboards like the whiteboard featured in Zoom allows for drawing, while Google's Jamboard provides possibilities for students to draw or to post sticky notes. More elaborate whiteboards, like Limnu or Mural, provide more possibilities for organizing students into groups, and to thematically organize student thinking. The sheer number of possible online tools meant that novice teachers needed to think carefully about their instructional goals in order to choose an online tool for instruction. They needed to know exactly how they wished to represent students' thinking, and what they wished for students to be able to do in their own whiteboard spaces. We see this requirement for backwards design as an affordance to conducting rehearsals online, as it means that novices needed to be very clear about what their instructional goals were for each portion of the lesson, and to ensure that the tools they selected would help them to meet these goals.

\section{Practicing Routines of Interaction}

In the rehearsal, novices are expected to practice routines of interaction (e.g., Lampert \& Graziani, 2009) that require them to enact specific discourse moves, for example eliciting student thinking using probing questions, or pressing students for deeper explanation based on the data they have generated. These routines also require novices to exercise professional judgment, for example, to diagnose misunderstandings, or to learn when it is appropriate to revoice students' ideas to more clearly 
communicate their intent. In this way, we encourage novice teachers to not only try out new discourse strategies or productive questioning, but also attend to developing the skill of responsiveness. Novices plan for these interactions by anticipating what questions they might ask students and what responses students might give. They have "back pocket questions" on hand to stimulate discussion and to respond to student thinking, as appropriate. In the online space, we found that novices were able to give additional time to these interactions, as the focus of their instruction was very much on interactions and not, for example, optimizing a demonstration or tinkering with equipment.

The role of the teacher educator during the rehearsal is to focus attention not just on the core practices the novices are engaged in, but also how they practice responsiveness to students' ideas by occasionally interjecting to point out opportunities to respond to students, or to remind novices of their instructional goals. Rehearsals in person take place as a free flow of teaching and interjection by the teacher educator, as well as feedback from other novice teachers in the class. Often these discussions can happen mid-rehearsal; for example, in response to a student's question we might pause the rehearsal and discuss what to do next or reflect back on the novice's instructional goals. A limitation of online instruction is that conversation is often stilted as overlapping talk is incomprehensible, video or audio feeds often freeze, and participants are often muted to avoid excess noise. This posed a challenge for us as teacher educators and caused us to reevaluate our roles in the approximation of practice. This meant that we refrained from interjecting during the rehearsal, and rather kept notes to share with the novice teachers and students at the end. This likely contributed to some "Zoom fatigue," as we noticed that contributions from fellow novices were limited towards the end of the rehearsals.

As we were using Zoom, we asked the co-instructors to take a smaller group of students into breakout rooms to engage them in modeling, and to orchestrate small group discussions. The teacher educator in this case remained in the "main room," rather than jumping back and forth to breakout rooms. This provided opportunities for novices to try out discourse practices on an even smaller scale, and without the looming presence of the teacher educator, but meant that we could only provide feedback after we had watched the novices' recordings of their breakout rooms. However, seeing that the teacher educator could not provide feedback to the novice teacher, we found that those novices acting as students often provided their own feedback to the instructors in the breakout room. This was an unanticipated affordance that stepping back from some aspects of the rehearsals provided. Peers began to act more like critical friends (e.g., Curry, 2008) and specifically discussed practices that worked or needed developing in the small group context.

Another affordance of the online environment was that novices often used virtual whiteboards to facilitate their modeling in small groups, and thus the teacher educator could monitor the modeling process without interrupting the small group discussion and get a sense of the progression of student thinking throughout the modeling process. A challenge of doing this modeling in separate breakout rooms was that when students came back to the whole group, the novices who were co-teaching with a peer needed to take a short break during the rehearsal to consult about what was discussed in their own small breakouts. 


\section{Tensions Inherent in Remote Instruction of Teaching Methods}

We have discussed details of a science teacher education course involving a new cohort of novice science teachers, whose teacher education program has been experienced entirely online. They have been learning about what teaching science should look like in school classrooms; yet ahead of their field experiences, they have been practicing their teaching entirely online. This is a tension in our programming, as these novice teachers will not have experienced modeled instruction in person, nor will they have practiced teaching in person, yet they will be expected to do so on their field experiences. For example, the novices in this course immediately moved on to participate in their first field experience, during which they are teaching online every second day. As novices move into their first field placements, this tension is compounded by the uncertainty created by pandemic-related closures of school buildings and classroom quarantines, on top of requirements for secondary students to be learning online half the time. These are exceptional circumstances in which to learn the practice of teaching, especially as many teachers in secondary schools have had to shift to hybrid forms of instruction. As educators continue to experience and adapt to changes in instructional formats at every level across elementary, secondary, and university contexts, novice teachers will similarly experience a shifting mix of practices in their own learning, in their rehearsals of instruction, and in their field experiences.

Our model for practice-based pedagogy was developed based on in-person instruction, even though novices are now learning how to do this virtually. Practice-based pedagogy, while helpful for novices in a teacher education program, is not intended to replicate actual classroom conditions. As discussed, rehearsals are approximations of teaching, deliberately reduced in complexity to focus on learning and rehearsing core practices. Class sizes are generally unrealistic, and novices are learning to teach towards an unrealistic student population. As teacher educators, we have experienced a tension in our creation of a simplified approximation of teaching for the purpose of rehearsing core practices (see Jao et al., 2018), but we now add a whole new dimension to this complexity. Virtual instruction with different class structures, unfamiliar conversation dynamics, and a variety of online tools, has increased the complexity of how we focus on the important practices of eliciting and responding to student thinking. Implementing practice-based pedagogy online augmented the perennial tension between flexible, responsive instruction, and structured, planned lessons. Because of the limitations of fluid conversation while videoconferencing, novice teachers were not able to engage with each other or with the instructors with the same level of spontaneity that emerges in face-to-face discussion. On the other hand, students were able to observe and rehearse structured dialogues and nonverbal discussions (e.g., digital whiteboards); practices that facilitate more equitable participation among students than verbal discussion alone.

A similar tension exists in the fact that our online science teaching methods courses do not currently provide resources for novices to learn about online science teaching practices. In our move to online instruction, we sought to maintain the overall objective of AST for student engagement with big ideas in science, despite the necessary shift in focus from in-person activities (e.g., hands-on activities or demonstrations) to online activities (e.g., videos, simulations, and message board discussions). This shift in mode of instruction revealed new possibilities for novice teachers to demonstrate responsiveness and flexibility, even while they were planning increasingly structured instructional activities. Despite having 
little exposure to online teaching practices, we observed that novices exercised creativity in planning and meaningfully incorporating online resources. In preparing their lessons, novice teachers critically examined educational videos from a range of sources (e.g., online games, simulations, public broadcasting, TikTok) for ways that they might elicit student thinking and provide evidence to engage student modelling.

\section{Future Considerations}

In reflecting on our experiences pivoting our science teaching methods courses online, we offer some considerations for future implementations of online practice-based pedagogy. One consideration for future teaching is the role of the interactive functions of videoconference platforms (e.g., chat boxes, polls, reactions) in lesson planning and instructional practice. We noticed that students were less likely to speak during online instruction, but often felt very comfortable using the chat function. One modification for future online approximations of teaching might be to incorporate the use of the chat to elicit and respond to student thinking. If instruction is happening in co-teaching pairs, novices could divide out the labour of facilitating the chat and leading the discussion. This could allow for spontaneity where it is otherwise limited in whole group discussions, as well as create spaces for participation by students not participating in verbal conversation.

We also note that while there are specifics to teaching science, novice teachers do not take science methods courses in isolation, and many core practices apply across disciplinary areas. There are opportunities to coordinate and collaborate across disciplinary, cross-curricular, and seminar/capstone courses in ways that may address some of the limitations identified above. For example, at Dawn's institution, novice teachers (both elementary and secondary) practiced synchronous teaching in their science methods course, while working to use similar core practices in the development of an asynchronous LES in their capstone courses. This practice was facilitated by the two courses being taught by the same instructor at the elementary level, and close collaboration with the capstone instructor at the secondary level; a situation we acknowledge does not always exist. As with synchronous instruction, the asynchronous planning and teaching requires significant consideration of what combination of platforms and apps better support the kind of responsiveness that is key to AST.

In conclusion, the principles and practices of AST and MBI are important to both in-person and online learning. However, teaching these practices in new virtual settings is not a simple matter of translating them to the online world. Reflecting on the core principles of our courses has challenged us to consider whether and how we have continued to teach in ways that foreground those principles, and indeed, whether they still hold true for virtual teaching environments. This process has required us to make the adaptations we discussed above, but has also afforded us the opportunities to rethink and reflect on our core practices in consideration of the shifting learning contexts of our students. We hope that the details of our first forays into online science teaching methods will invite others to reflect with us on practices of pedagogy as educators continue to face the ongoing challenges of hybrid, online, and in-person instruction alongside novice teachers, in the new virtual landscape of instruction. 


\section{References}

Curry, M. (2008). Critical friends groups: The possibilities and limitations embedded in teacher professional communities aimed at instructional improvement and school reform. Teachers College Record, 110(4), 733-774.

Grossman, P., Hammerness, K., \& McDonald, M. (2009). Redefining teaching, re-imagining teacher education. Teachers and Teaching: Theory and Practice, 15(2), 273-289.

Harlen, W. (Ed.). (2010). Principles and big ideas of science education. Association for Science Education.

Jao, L., Wiseman, D., Kobiela, M., Gonsalves, A., \& Savard, A. (2018). Practice-based pedagogy in mathematics and science teaching methods: Challenges and adaptations in context. Canadian Journal of Science, Mathematics and Technology Education, 18(2), 177-186. https://doi.org/10.1007/s42330018-0009-0

Kavanagh, S. S., Metz, M., Hauser, M., Fogo, B., Taylor, M. W., \& Carlson, J. (2020). Practicing responsiveness: Using approximations of teaching to develop teachers' responsiveness to students' ideas. Journal of Teacher Education, 71(1), 94-107.

Lampert, M., Franke, M. L., Kazemi, E., Ghousseini, H., Turrou, A. C., Beasley, H., Cunard, A., \& Crowe, K. (2013). Keeping it complex: Using rehearsals to support novice teacher learning of ambitious teaching. Journal of Teacher Education, 64(3), 226-243. https://doi.org/10.1177/0022487112473837

Lampert, M., \& Graziani, F. (2009). Instructional activities as a tool for teachers' and teacher educators' learning. The Elementary School Journal, 109(5), 491-509.

McDonald, M., Kazemi, E., \& Kavanagh, S. S. (2013). Core practices and pedagogies of teacher education: A call for a common language and collective activity. Journal of Teacher Education, 64(5), $378-386$.

Ministère de l'Éducation (MELS). (2006). Evaluation of learning at the secondary level. https://bit.ly/39LpsTU

Moje, E. B. (2015). Doing and teaching disciplinary literacy with adolescent learners: A social and cultural enterprise. Harvard Educational Review, 85(2), 254-278.

Quillin, K., \& Thomas, S. (2015). Drawing-to-learn: A framework for using drawings to promote modelbased reasoning in biology. CBE-Life Sciences Education, 14(1), es2.

Stieff, M., \& DeSutter, D. (2021). Sketching, not representational competence, predicts improved science learning. Journal of Research in Science Teaching, 58(1), 128-156.

UNESCO. (2020). What have we learnt? Overview of findings from a survey of ministries of education on national responses to COVID-19. https://unesdoc.unesco.org/ark:/48223/pf0000374702

Windschitl, M., \& Thompson, J. (2013). The modeling toolkit: Making student thinking visible with public representations. The Science Teacher, 80(6), 63-69.

Windschitl, M., Thompson, J., \& Braaten, M. (2008). Beyond the scientific method: Model-based inquiry as a new paradigm of preference for school science investigations. Science Education, 92(5), 941-967. 
Windschitl, M., Thompson, J., \& Braaten, M. (2018). Ambitious science teaching. Harvard Education Press.

Windschitl, M., Thompson, J., Braaten, M., \& Stroupe, D. (2012). Proposing a core set of instructional practices and tools for teachers of science. Science Education, 96(5), 878-903.

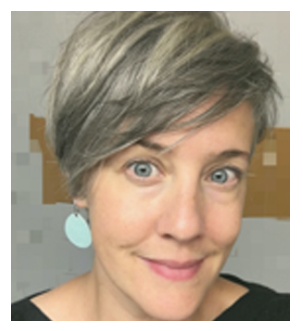

Allison J. Gonsalves is an Assistant Professor in the Department of Integrated Studies in Education at McGill University. Her research interests are in the area of science identities with a focus on gender and equity in higher education and out of school science learning contexts. Dr. Gonsalves has taught elementary and secondary science teaching methods courses at McGill University for over ten years and has used practice-based pedagogies in her classes since 2014. 2020 was the first time she has engaged in any form of online instruction.

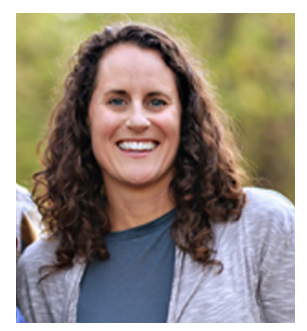

Emily Diane Sprowls is a PhD student in the Department of Integrated Studies in Education at McGill University. She is interested in collaborative learning among students, teachers and scientists in the contexts of science outreach and environmental/sustainability education. Prior to her doctoral studies, Emily enjoyed learning and exploring science with young people as a secondary school teacher for 15 years. Alongside her classroom teaching, she has mentored pre-service teachers in their practica, and coached in-service teachers on pedagogical practices in her role as a Critical Friends Group facilitator. The 2020 year was the first time she ever taught online.

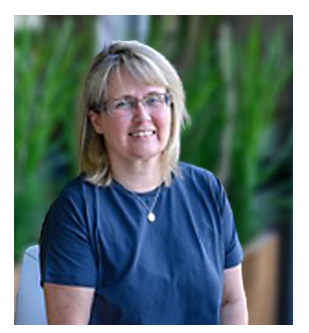

Dawn Wiseman is an Associate Professor in the School of Education at Bishop's University. Her research focuses on the manner in which Indigenous and Western ways of knowing, being, and doing might circulate together in STEM/STEAM teaching and learning (kindergarten through post-secondary education) and student-directed inquiry. Dr. Wiseman teaches courses in elementary and secondary science methods, research methods, and interdisciplinary teaching and learning. She has used practice-based pedagogies in her classes since 2015, and 2020 was the first time she has engaged in any form of online instruction. 